\title{
Erratum
}

\section{Direct Oxidative Conversion of Primary Alcohols to Nitriles Using Molecular Iodine in Ammonia Water}

Naoshi Mori, Hideo Togo* Synlett 2005, 1456.

In the introduction, it was mentioned that there has only been one report for the direct oxidative conversion of alcohols to nitriles in a one-pot procedure [using $\mathrm{NH}_{4} \mathrm{HCO}_{3} /\left(\mathrm{Bu}_{4}\right)_{2} \mathrm{~S}_{2} \mathrm{O}_{8} / \mathrm{cat}$. $\mathrm{Cu}\left(\mathrm{HCO}_{2}\right)_{2} \cdot \mathrm{Ni}\left(\mathrm{HCO}_{2}\right)_{2}$ in aq. $\mathrm{KOH}$ and $i$-PrOH].

However, another method, using $\mathrm{MnO}_{2}, \mathrm{NH}_{3}$ and $\mathrm{MgSO}_{4}$ in $i$-PrOH-THF on activated alcohols such as benzylic and cinnamic alcohols, has also been reported: 'Tandem Oxidation Processes: The Direct Conversion of Activated Alcohols into Nitriles' - McAllister, G. D.; Wilfred, C. D.; Taylor, R. J. K. Synlett 2002, 1291. 